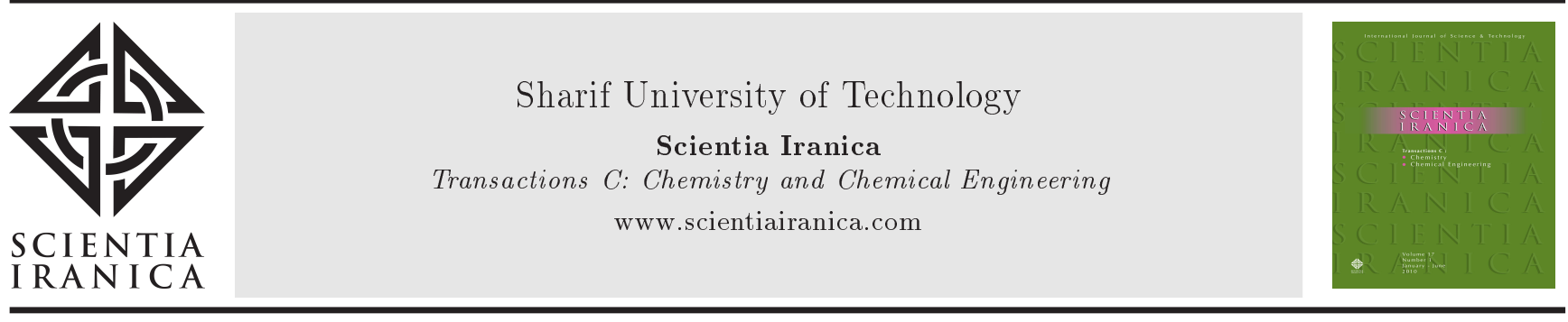

\title{
Investigation of the effects of carbonic agent and nanoclay on the properties of the polylactic acid-based nanocomposites
}

\author{
M. Coban ${ }^{a}$, S. Hazer ${ }^{a}$ and A. Aytac ${ }^{a, b, *}$ \\ a. Department of Chemical Engineering, Engineering Faculty, Kocaeli University, 41380, Kocaeli/Turkey. \\ b. Polymer Science and Technology Programme, Kocaeli University, 41380, Kocaeli/Turkey.
}

Received 5 January 2017; received in revised form 12 April 2017; accepted 21 August 2017

\section{KEYWORDS}

Poly(lactic acid);

Flame retardant;

Triphenyl phosphate

(TPP).

\begin{abstract}
The objective of this study is to investigate the effects of carbonic agent and nanoclay loading level on the properties of the added flame retardant and plasticized polylactic acid (PLA) composites. Pentaerythritol (PER) was used as a carbonic agent in the composites. The flammability behaviour of these composites was investigated with the increasing nanoclay loading level. Flame retardant properties of plasticized PLA composites, which consist of PER and nanoclay as a synergistic agent, were evaluated. While the nanoclay loading levels were changed between 1-5 wt\% of these samples, PER loading levels were fixed at $2 \mathrm{wt} \%$. Besides, effects of increased PER loading level were also investigated with 3 wt\% clay loading. Samples were produced by extrusion and injection molding techniques. The morphological, thermal, and mechanical properties were studied. The flammability was evaluated by Limiting Oxygen Index (LOI) and vertical burning test (UL-94). The results showed that the increased PER level did not significantly change LOI values of the PLA-based nanocomposites. In addition, the highest LOI value was observed as 32 for $1 \mathrm{wt} \%$ nanoclay including a sample. While adding PER to the PLA/PEG/TPP increased the elongation at break value, addition of the nanoclay decreased this value for nanocomposites.
\end{abstract}

(C) 2017 Sharif University of Technology. All rights reserved.

\section{Introduction}

Poly (lactic acid) (PLA) is a biodegradable polymer which belongs to aliphatic polyester family, and it is a thermoplastic substance that can be made from renewable resources $[1,2]$. In recent years, because of environmental pollution and rapid decrease of oilbased energy sources, the increasing attention to environment-friendly and biodegradable polymers was

*. Corresponding author. Tel.:+90 26230335 32;

Fax: +90 262 3591262

E-mail address: aaytac@kocaeli.edu.tr (A. Aytac) observed. Among the biodegradable polymers, PLA is a promising polymer with appropriate physical properties as well as low production cost of renewable energy sources which can be substituted for petroleum-based polymers [3,4]. For these reasons, PLA has been used in various industrial areas. However, the flammability property of PLA is restricted to be used in some important areas such as the electronic and automotive industries. PLA is a flammable polymer and its Limiting Oxygen Index (LOI) value is approximately 19-20 [3]. Therefore, the flammability property of PLA needs to be improved. A flammability property of PLA is enhanced through the addition of the flame retardant materials. In the literature, when the flame retardant materials are added to the PLA matrix, the decrease 
Table 1. Compositions of the flame retardant PLA samples.

\begin{tabular}{lccccc}
\hline Component & $\begin{array}{c}\text { PLA } \\
(\mathbf{w t} \%)\end{array}$ & $\begin{array}{c}\text { PEG } \\
(\mathbf{w t} \%)\end{array}$ & $\begin{array}{c}\text { TPP } \\
(\mathbf{w t} \%)\end{array}$ & $\begin{array}{c}\text { PER } \\
(\mathbf{w t} \%)\end{array}$ & $\begin{array}{c}\text { Nanoclay } \\
(\mathbf{w t})\end{array}$ \\
\hline PLA/PEG/TPP & 81 & 9 & 10 & - & - \\
PLA/PEG/TPP/PER & 81 & 9 & 8 & 2 & - \\
PLA/PEG/TPP/PER/1NC & 81 & 9 & 7 & 2 & $\mathbf{1}$ \\
PLA/PEG/TPP/PER/3NC & 81 & 9 & 5 & $\mathbf{2}$ & $\mathbf{3}$ \\
PLA/PEG/TPP/PER/5NC & 81 & 9 & 3 & 2 & $\mathbf{5}$ \\
PLA/PEG/TPP/4PER/3NC & 81 & 9 & 3 & $\mathbf{4}$ & 3 \\
PLA/PEG/TPP/6PER/3NC & 81 & 9 & 3 & $\mathbf{6}$ & 3 \\
\hline
\end{tabular}

of its toughness values is seen. For this reason, it is proposed to improve toughness and flammability simultaneously [5]. Generally, Poly(ethylene glycol) (PEG) is used as a toughening and charring agent because of hydroxyl groups in the structure $[4,5]$. Another way to improve flammability behaviour of PLA is using Intumescent Flame Retardant (IFR). IFR includes three components: a carbonization agent, a blowing agent, and an acid source [6]. In the literature, there are a few studies on the flame retardant properties of PLA with IFR system. Besides, to the best of authors' knowledge, TPP/PER intumescent system has not been used for plasticized PLA before. Reti et al. reported about APP/PER, IFR on the properties of PLA. They compared this system to the materials including starch and lignin; PLA/APP/PER showed higher LOI value [7]. Zhan and $\mathrm{Hu}$ et al. produced an intumescent flameretardant spirocyclic pentaerythritol bisphosphorate diphosphoryl melamine (SPDPM) and found good flammability property as the flame retardant achieved loading level of $25 \mathrm{wt} \%$ [8]. Sahabanian et al. studied on a potential promoter in order to gain the flame retardancy of PLA/ammonium polyphosphate (APP) system, and so a novel polyamide (PA) containing aromatic and aliphatic groups was produced and characterized by different structural methods [9]. They found that, to some extent, PA shows a synergistic effect on improving the flame retardancy properties of PLA composites at the fixed mass ratio 2:1 of APP and PA. Liu et al. prepared the novel intumescent flame-retardant poly(lactic acid) (PLA/IFR)/organomodified $\alpha$-zirconium phosphate(OZrP) nanocomposites [10]. They showed that OZrP could enhance the residue in TGA and significantly improve the flame retardancy of PLA/IFR/OZrP nanocomposites, showing an excellent synergistic effect. Fukushima and Murariu et al. used two different nanofillers: expanded graphite and organically modified montmorillonite for PLA-based nanocomposites [11]. They found that the dispersed graphite nanolayers in PLA significantly enhance the polyester crystallization; besides, the essential increase of thermal resistance is essentially linked to the addition of organoclay.

In this study, different from the literature, TPP/PER intumescent system was used in the plasticized PLA. Polyethylene glycol (PEG) was chosen as a plasticizer to improve toughness of the nanocomposites. Then, flammability behaviour of these composites was investigated with the increasing nanoclay loading level. Besides, effects of increased PER loading level were also investigated at the fixed nanoclay loading level (3 wt\%). The morphological, thermal, mechanical, and flammable properties of the composites were studied.

\section{Material and methods}

\subsection{Materials}

Poly(lactic acid) (Natureplast, PLI005 MFI: 5-7 g/10 min. $190^{\circ} \mathrm{C}$ ) was used as the matrix material plasticized polyethylene glycol(PEG) $\left(\mathrm{M}_{w}:\right.$ 8000) in this study. TPP (Triphenyl Phosphite) (Across) was used as flame retardant. Nano additive nanoclay was supplied from ESAN Eczacıbaçı. Pentaerythritol (PER) was supplied from MKS Marmara.

\subsection{Preparation samples}

PLA was dried in a vacuum oven at $80^{\circ} \mathrm{C}$ for $12 \mathrm{~h}$. Nanoclay was dried in a vacuum oven at $50^{\circ} \mathrm{C}$ for 4 hours. The composite preparations (Table 1) were performed in a laboratory scale co-rotating twin-screw mini extruder (DSM Xplore $15 \mathrm{ml}$ Micro-compounder) at $200^{\circ} \mathrm{C}, 100 \mathrm{rpm}$ during $3 \mathrm{~min}$. After mixing, the samples were molded by a laboratory-scale injection molding machine with a barrel temperature of $200^{\circ} \mathrm{C}$, a mold temperature of $25^{\circ} \mathrm{C}$, and 10 bar injection pressure.

\subsection{Characterization}

Tensile test was performed according to ISO $5275 \mathrm{~A}$ using Instron trademark of universal testing machine. The dimensions of the test samples were $4 \mathrm{~mm}$ in 
width, $2.10 \mathrm{~mm}$ in thickness, and $30 \mathrm{~mm}$ in length [12]. The tensile test speed was $5 \mathrm{~mm} / \mathrm{min}$ at $25^{\circ} \mathrm{C}$. Tensile strength and tensile strain values of composites were found. Five specimens of each sample were used for tensile test.

Differential Scanning Calorimetry (DSC) analysis was realized for measuring glass transition temperature $\left(T_{g}\right)$, melting temperature $\left(T_{m}\right)$, heat of fusion $\left(\Delta H_{\text {matrix }}\right)$, and degree of crystallinity $\left(X_{c}\right)$ under nitrogen atmosphere by Mettler Toledo DSC machine. Samples were heated from $25^{\circ} \mathrm{C}$ to $200^{\circ} \mathrm{C}$ at a heating rate of $10^{\circ} \mathrm{C} \cdot \mathrm{min}^{-1}$ and held at the temperature for 5 min. Then, it was cooled from $200^{\circ} \mathrm{C}$ to $25^{\circ} \mathrm{C}$ at a cooling rate of $10^{\circ} \mathrm{C} \cdot \mathrm{min}^{-1}$. The degree of crystallinity of composites was determined according to PLA by thermal properties with the following equation [12]:

$$
X_{c}(\% \text { crystallinity })=\frac{\Delta H_{m}-\Delta H_{c}}{\left(\omega_{f}\right)^{*} \Delta H_{m}^{0}} .
$$

$\Delta H_{m}$ is the heat of fusion of each sample, $\Delta H_{c}$ is the crystallization enthalpy, $\omega_{f}$ is the weight fraction, and $\Delta H_{m}^{0}$ is the heat of fusion of the matrix. Heat of fusion of PLA $\left(\Delta H_{m}^{0}\right)$ was taken as $93.7 \mathrm{~J} / \mathrm{g}$ [12].

TGA (thermogravimetric analysis) analysis was carried out by Mettler Toledo TGA Star trademark machine. Samples were heated from $25^{\circ} \mathrm{C}$ to $800^{\circ} \mathrm{C}$ at a heating rate of $10^{\circ} \mathrm{C} \cdot \mathrm{min}^{-1}$ under the nitrogen atmosphere. Then, $95 \mathrm{wt} \%$ and $5 \mathrm{wt} \%$ decomposition temperatures were determined.

Limiting Oxygen Index (LOI) values were tested by Mares Analysis Instrument oxygen meter (M-LOI01 ) according to the TS 11162-2 /ISO 4589-2 standard. The sample which is to be marked $50 \mathrm{~mm}$ was held vertically in the transparent chimney, where the flow of oxygen and nitrogen was controlled. The issue of whether the burning length passes $50 \mathrm{~mm}$, limit or not was reported. The LOI test was repeated under different concentrations of oxygen and nitrogen to determine the minimum concentration of oxygen needed for burning the sample. Vertical burning ratings (UL-
94) were obtained via vertical burning test instrument according to the ASTM D3801 testing procedure. The sizes of the products tested were $80 \mathrm{~mm} \times 10 \mathrm{~mm} \times$ $4 \mathrm{~mm}$.

\section{Result and discussion}

\subsection{Mechanical characteristics}

Tensile strength $(\mathrm{MPa})$ values of increasing loading level nanoclay and PER for plasticized PLA/TPP/ PER samples were given in Figure $1(\mathrm{a})$ and (b). It was observed that the tensile strength value decreased with the addition of PER to the PLA/PEG/TPP sample (Figure 1(a)). Besides, the addition of $1 \mathrm{wt} \%$ nanoclay to the PLA/PEG/ TPP/PER positively affected the tensile strength; however, that value decreased by the increasing loading level of the nanoclay. 3 wt\% nanoclay, including the sample, was selected to investigate the effect of increasing loading level PER (2-4-6 wt\%) on the tensile properties. The highest tensile strength was obtained from PLA/PEG/TPP/4PER/3NC nanocomposite. The tensile strength value increased approximately $40 \%$ for $4 \mathrm{wt} \%$ PER including the sample.

Strain at break values, including various loading levels of nanoclay, and PER for plasticized PLA/TPP/PER samples are given in Figure 2(a) and (b), respectively. TPP/PER, IFR system increased the strain at break value $(22 \%)$; however, addition of nanoclay decreased the strain at break values. PLA/PEG/TPP/PER/1NC sample showed the highest strain at break value among samples including nanoclay. (Figure 2(a)). Increasing PER loading level did not change strain at break values (Figure 2(b)).

\subsection{Thermal properties}

DSC is a commonly used technique for the assessment of the crystallization and melting behaviors of polymers [4]. DSC results of the prepared samples are as shown Table 2. The glass transition temperature of neat-PLA is $59^{\circ} \mathrm{C}$. The addition of PEG as a plasticizer

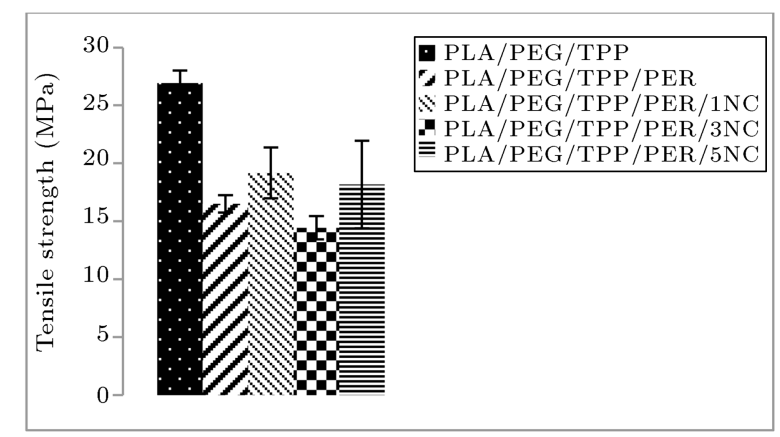

(a)

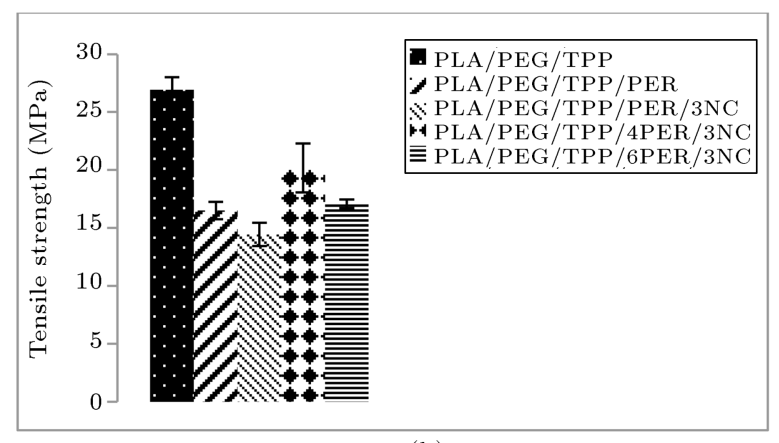

(b)

Figure 1. Tensile strength test results including various loading levels of nanoclay (a) and various loading levels of PER (b) for plasticized PLA/TPP/PER samples. 


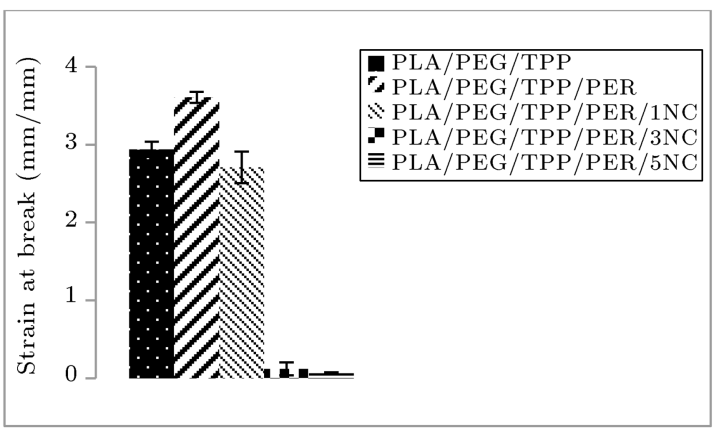

(a)

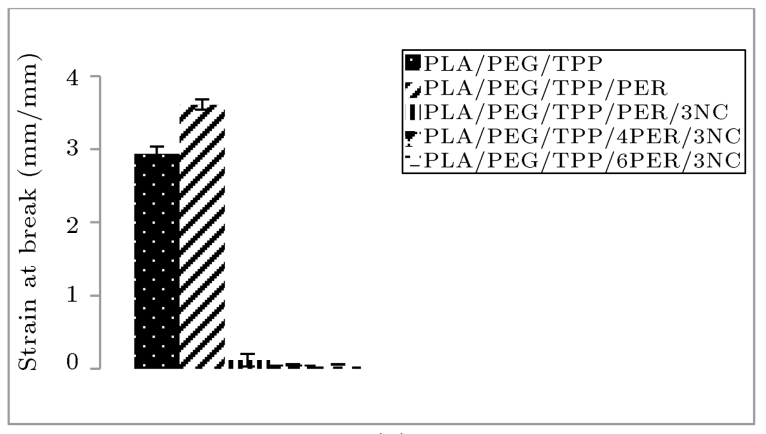

(b)

Figure 2. Strain at break values including various loading levels of nanoclay (a) and various loading levels of PER (b) for plasticized PLA/TPP/PER samples.

Table 2. DSC results for all prepared samples.

\begin{tabular}{lccccc}
\hline Samples & $\boldsymbol{T}_{\boldsymbol{g}}$ & $\boldsymbol{T}_{\boldsymbol{m}}$ & $\boldsymbol{\Delta} \boldsymbol{H}_{\boldsymbol{m}}(\mathbf{J} / \mathbf{g})$ & $\boldsymbol{\Delta} \boldsymbol{H}_{\boldsymbol{c}}(\mathbf{J} / \mathbf{g})$ & $\boldsymbol{X}_{\boldsymbol{c}, \boldsymbol{P} \boldsymbol{L} \boldsymbol{A}}(\boldsymbol{\%})$ \\
\hline PLA/PEG/TPP & 54.8 & 149.6 & 21.06 & 6.80 & 18.8 \\
PLA/PEG/TPP/PER & 52.7 & 146.9 & 25.34 & 11.34 & 18.4 \\
PLA/PEG/TPP/PER/1NC & 53.2 & 148.3 & 25.47 & 13.28 & 16.1 \\
PLA/PEG/TPP/PER/3NC & 48.8 & 148.7 & 24.72 & 14.22 & 13.8 \\
PLA/PEG/TPP/PER/5NC & 47.9 & 149.8 & 26.45 & - & 36.0 \\
PLA/PEG/TPP/4PER/3NC & 47.2 & 148.7 & 27.32 & 11.17 & 21.3 \\
PLA/PEG/TPP/6PER/3NC & 46.4 & 149.9 & 26.53 & 18.35 & 10.1 \\
\hline
\end{tabular}

Table 3. TGA results.

\begin{tabular}{lcccc}
\hline & \multicolumn{2}{c}{ The decomposition temperature in nitrogen } & \\
\cline { 2 - 3 } Samples & $\begin{array}{c}\mathbf{5 \%} \text { by weight of } \\
\text { decomposition } \\
\left({ }^{\circ} \mathbf{C}\right)\end{array}$ & $\begin{array}{c}\mathbf{9 5 \%} \\
\text { decomposition } \\
\left({ }^{\circ} \mathbf{C}\right)\end{array}$ & $\begin{array}{c}\mathbf{5 0 \%} \text { by weight of } \\
\text { decomposition } \\
\left({ }^{\circ} \mathbf{C}\right)\end{array}$ & $\begin{array}{c}\text { Char residues at } \\
\mathbf{8 0 0} \mathbf{C}(\%)\end{array}$ \\
\hline PLA/PEG/TPP & 315.6 & 393.0 & 369.8 & 0.0 \\
PLA/PEG/TPP/PER & 274.2 & 408.5 & 365.4 & 0.3 \\
PLA/PEG/TPP/PER/1NC & 282.3 & 397.1 & 364.6 & 0.0 \\
PLA/PEG/TPP/PER/3NC & 283.1 & 402.1 & 364.2 & 0.0 \\
PLA/PEG/TPP/PER/5NC & 291.7 & 410.3 & 360.8 & 1.6 \\
PLA/PEG/TPP/4PER/3NC & 284.4 & 428.0 & 359.7 & 2.7 \\
PLA/PEG/TPP/6PER/3NC & 288.5 & 423.7 & 356.3 & 1.9 \\
\hline
\end{tabular}

to the neat-PLA caused a decrement in $T_{g}$. This reduction is slightly recovered as a result of the presence of TPP in the plasticized PLA. Besides, the increasing loading level of nanoclay decreased the $T_{g}$ values of the samples. The voids formed in polymer matrix were seen in SEM analysis as a result of the increment of the PER foaming agent. The voids increased polymer chain mobility; thus, $T_{g}$ values decreased when PER amount increased. The melting temperature values $\left(T_{m}\right)$ of all formulations were slightly changed. The degree of crystallinity $\left(X_{c}\right)$ value of the PLA/PEG/TPP was unaffected by the addition of PER. Maximum crystallinity value was observed in the sample including $5 \%$ nanoclay.

Thermal stability of the samples was analysed by TGA analysis. TGA results are summarized in Table 3. According to the table, onset of the decomposition temperature for all composites is more than $200^{\circ} \mathrm{C}$. This temperature is the processing temperature in the extruder; for this reason, it can be said that samples do not degrade during the production process. $50 \mathrm{wt} \%$ loss of temperature was not significantly changed for all prepared samples. The increasing loading level of PER enhanced the char residue percentage. 
Table 4. UL-94 and LOI test results.

\begin{tabular}{lcccc}
\hline Samples & UL-94 & Dripping & Ignition the cotton & LOI \\
\hline PLA/PEG/TPP & V-0 & Yes & No & 30.3 \\
PLA/PEG/TPP/PER & V-0 & Yes & No & 30.7 \\
PLA/PEG/TPP/PER/1NC & V-0 & Yes & No & 32.3 \\
PLA/PEG/TPP/PER/3NC & V-0 & Yes & No & 30.9 \\
PLA/PEG/TPP/PER/5NC & V-0 & Yes & No & 30.3 \\
PLA/PEG/TPP/4PER/3NC & V-0 & Yes & No & 30.7 \\
PLA/PEG/TPP/6PER/3NC & V-0 & Yes & No & 30.6 \\
\hline
\end{tabular}

\subsection{Flammability properties}

The vertical burning rating tests (UL-94) were widely used to utilize the flame retardant properties and to evaluate the plastic dripping of samples. Table 4 exhibits UL-94 rating values of the prepared samples. Results are obtained in V-0 classification for all kinds of samples. The dripping was observed, but none of the samples did flame. LOI is commonly used for the determination of the relative flammability of polymeric materials [7]. LOI values of the prepared samples are summarized in Table 4 . The highest value was observed as 32.3 for the 1 wt.\% samples including nanoclay. In addition, when the loading level of PER increased in the sample, the LOI values of the samples did not change. Increasing LOI value in the IFR system was explained by forming a char layer on the surface, and this char layer acts as a physical barrier, which prevents the materials from the heat and mass transfer through the gas and the condensed phases [2,13-15].

\subsection{Scanning Electron Microscope (SEM)}

Morphologies of the tensile fracture surface of the prepared samples were investigated by SEM analysis. Micrographs of the SEM are shown in Figure 3(a)-(d). Homogenous dispersion and plastic deformation were observed in SEM micrographs of the PLA/PEG/TPP sample. When PER was added to these samples, plastic deformation decreased and homogeneous structure was protected (Figure 3(b)). The voids' formations were seen by adding nanoclay to this sample (Figure 3(c)). Besides, the voids' amount increased with the enhancing of the nanoclay loading level.

\section{Conclusion}

An intumescent flame retardant PLA-based nanocomposite system was investigated in this study. The flammability behaviour of these composites was investigated separately with the increasing nanoclay and PER loading level. The highest LOI value was observed as 32.3 for samples that included $1 \mathrm{wt} \%$ nanoclay. In addition, when the loading level of PER increased in the sample, the LOI value of the samples did not change. Increasing LOI value in the IFR system was explained by forming a char layer on the surface. This char layer acts as a physical barrier, which prevents the materials from the heat and mass transfer between the gas and the condensed phases. UL-94 rating results were obtained in V-0 classification for all kinds of samples. The dripping was observed, but none of the
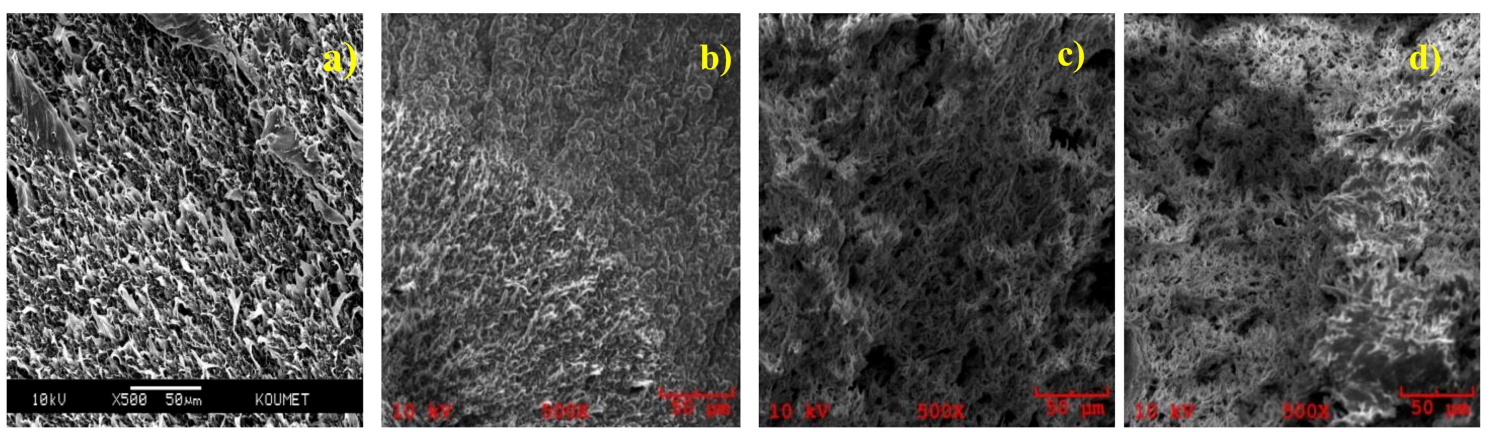

Figure 3. SEM micrograph of composites: (a) PLA/PEG/TPP, (b) PLA/PEG/TPP/PER, (c) PLA/PEG/TPP/PER/ $1 \mathrm{NC}$, and (d) PLA/PEG/TPP/PER/3NC. 
samples did flame. The tensile strength value decreased with the addition of PER to the control sample. The increasing PER loading level did not change the strain at break values. The addition of $1 \mathrm{wt} \%$ nanoclay to the PLA/PEG/TPP/PER positively affected the tensile strength, but that value decreased by the increasing loading level of the nanoclay. Homogenous dispersion and plastic deformation were observed in SEM micrographs of the PLA/PEG/TPP sample. The void formations were seen in the SEM micrographs of the $1 \mathrm{wt} \%$ nanoclay including the sample. Increasing the loading level of nanoclay decreased $T_{g}$ values of the samples. The degree of crystallinity $\left(X_{c}\right)$ value of the PLA/PEG/TPP was unaffected by the addition of PER.

\section{Acknowledgements}

The authors thank Scientific Research Projects Unit of Kocaeli University (KOUBAP) for financial support under Project number 2015/043.

\section{Abbreviations}

$\begin{array}{ll}\text { PEG } & \text { Poly(ethylene glycol) } \\ \text { PLA } & \text { Poly(lactic acid) } \\ \text { TPP } & \text { Triphenyl phosphate } \\ \text { PER } & \text { Pentaerythritol } \\ \text { IFR } & \text { Intumescent Flame Retardant } \\ \text { LOI } & \text { Limiting Oxygen Index } \\ \text { UL-94 } & \text { Vertical burning } \\ \text { DSC } & \text { Differential Scanning calorimetry } \\ \text { TGA } & \text { Thermogravimetric analysis }\end{array}$

\section{References}

1. Garlotta, D. "A literature review of Poly(Lactic Acid)", Journal of Polymers and the Environment, 9(2), pp. 63-84 (2001).

2. Bourbigot, S. and Fontaine, G. "Flame retardancy of polylactide: an overview", Polymer Chemistry, 1, pp. 1413-1422 (2010).

3. Wang, D.Y., Leuteritz, A., Wang, Y.Z., Wagenknecht, U. and Heinrich, G. "Preparation and burning behaviors of flame retarding biodegradable poly(lactic acid) nanocomposite based on zinc aluminum layered double hydroxide", Polymer Degradation and Stability, 95(12), pp. 2474-2480 (2010).

4. Wei, L.L., Wang, D.Y., Chen, H.B., Chen, L., Wang, X.L. and Wang, Y.Z. "Effect of a phosphorus containing flame retardant on the thermal properties and ease of ignition of poly(lactic acid)", Polymer Degradation and Stability, 96(9), pp. 1557-1561 (2011).
5. Song, Y.P., Wang, D.Y., Wang, X.L., Lin, L. and Wang, Y.Z. "A method for simultaneously improving the flame retardancy and toughness of PLA", Polym. Adv. Technol., 22, pp. 2295-2301 (2011).

6. Lv, P., Wang, Z., Hu, K. and Fan, W. "Flammability and thermal degradation of flame retarded polypropylene composites containing melamine phosphate and pentaerythritol derivatives", Polymer Degradation and Stability, 90, pp. 523-534 (2005).

7. Réti, C., Casetta, M., Duquesne, S., Bourbigot, S. and Delobel, R. "Flammability properties of intumescent PLA including starch and lignin", Polym. Adv. Technol., 19, pp. 628-635 (2008).

8. Zhan, J., Song, L., Nie, S. and Hu, Y. "Combustion properties and thermal degradation behaviour of polylactide with an effective intumescent flame retardant", Polym. Degrad. Stab., 94, pp. 291-296 (2009).

9. Shabanian, M., Kanga, N., Wanga, D., Wagenknechtb, U. and Heinrichb, G. "Synthesis of aromatic-aliphatic polyamide acting as adjuvant in polylactic acid (PLA)/ammonium polyphosphate (APP) system", Polym. Degrad. Stab., 98, pp. 1036-1042 (2013).

10. Fukushima, K., Murariu, M., Camino, G. and Dubois, P. "Effect of expanded graphite/layered-silicate clay on thermal, mechanical and fire retardant properties of poly(lactic acid)", Polym. Degrad. Stab., 95, pp. 1063-1076 (2010).

11. Liu, X.Q., Wang, D.Y., Wang, X.L., Chen, L. and Wang, Y.Z. "Synthesis of organo-modified $\alpha$-zirconium phosphate and its effect on the flame retardancy of IFR poly(lactic acid) systems", Polym. Degrad. Stab., 96, pp. 771-777 (2011).

12. Karsli, N.G. and Aytac, A. "Properties of alkali treated short flax fiber reinforced poly(lactic acid)/polycarbonate composites", Fibers and Polymers, 15(12), pp. 2607-2612 (2014).

13. Reti, C., Casetta, M., Duquesne, S., Delobel, R., Soulestin, J. and Bourbigot, S. "Intumescent biobasedpolylactide films to flame retard nonwovens", Journal of Engineered Fibers and Fabrics, 4(2), pp. 33-39 (2009).

14. Bourbigot, S., Bras, M.L., Delobel, R., Decressain, R. and Amoureux, J.P. "Synergistic effect of zeolite in an intumescent process: study of the carbonaceous structures using solid-state NMR", J. Chem. Soc. Faraday Trans., 92, pp. 149-158 (1996).

15. Riva, A., Camino, G., Fomperie, L. and Amiqouet, P. "Fire retardant mechanism in intumescent ethylene vinyl acetate compositions", Polym. Degrad. Stab., 82, pp. $341-346$ (2003).

\section{Biographies}

Meral Coban completed her BS degree from Kocaeli University in 2014. She is currently an MS candidate at Chemical Engineering Department of Kocaeli University, Turkey. Her research area includes polymer 
technology, polymer characterization, and flame retardant materials.

Seda Hazer obtained her BS degree from Beykent University in 2013 and is currently an MS candidate at Chemical Engineering Department of Kocaeli University, Turkey. Her research area includes polymer blends and fiber reinforced composites.
Ayse Aytac received her BSc degree in Chemical Engineering from the Hacettepe University in 1997. She received $\mathrm{MSc}$ and $\mathrm{PhD}$ degrees in Chemical Engineering from the Kocaeli University, Turkey. She has been working as an Associate Professor at Kocaeli University since 2000. She has worked in different projects in the field of polymer technology, polymer characterization, and polymer composites. 